\title{
Development of zinc oxide varistors
}

\author{
H S KALSI and B K DAS \\ National Physical Laboratory, New Delhi 110 012, India.
}

MS received 10 June 1982; revised 30 August 1982

Abstract. Grain growth kinetics of $\mathrm{ZnO}$ ceramics containing $6 \%$ additives of $\mathrm{Bi}_{2} \mathrm{O}_{3}, \mathrm{CoO}$ and $\mathrm{MnO}$ in equal molar ratios has been studied in the temperature range 1000 to $1350^{\circ} \mathrm{C}$. It has been observed that the grain growth data fits the $D^{2}=k t$ law and the activation energy computed from the rate constants is $65 \mathrm{kcal} / \mathrm{mol}$.

Keywords. Zinc oxide; voltage - dependent resistors; varistors; surge suppressors; metal oxide varistors.

\section{Introduction}

Voltage-dependent resistors or varistors are extensively used as surge suppressors in various electronic devices (Harnden et al 1972). These are usually made of silicon carbide to which various oxides like $\mathrm{SiO}_{2}, \mathrm{P}_{2} \mathrm{O}_{5}$ and $\mathrm{Al}_{2} \mathrm{O}_{3}$ are added. Recently another class of ceramics based on zinc oxide has been developed, which gives much superior varistor action as compared to silicon-carbide varistor (Matsouka et al 1969, 1970; Frosch 1954; Dienel 1956).

The current $(I)$ through a varistor at a voltage $(V)$ can be given as :

$$
I=K V^{n}=(V / C)^{n}
$$

where $n$ is the nonlinearity exponent and $C$ is the nonlinear resistance. The nonlinearity

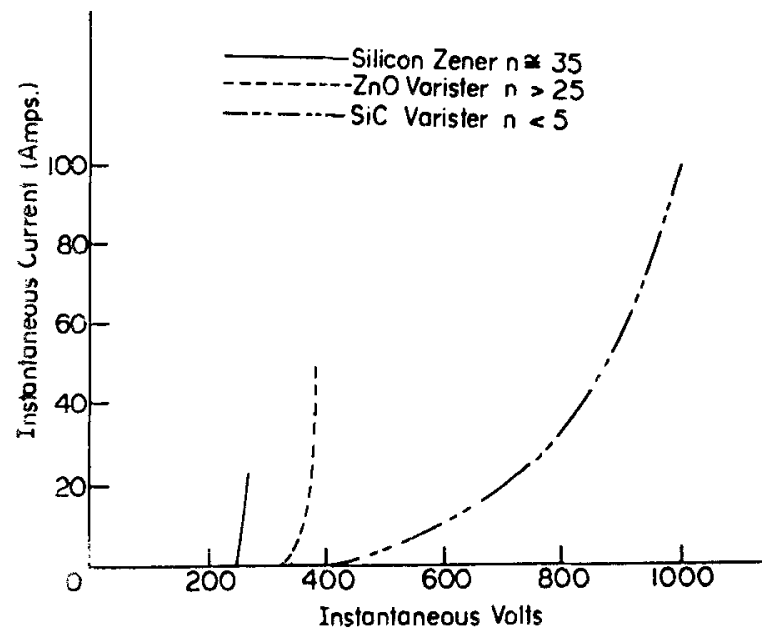

Figure 1. Instantaneous voltage of silicon zener, zinc oxide varistor and silicon carbide varistor vs their instantaneous current. 
coefficient for various types of varistors is shown in figure 1 . It can be seen that the performance of the zinc oxide varistor is comparable to that of a zener diode (Mcafee et al 1951; Mckay 1954).

It has earlier been reported that the varistor action in zinc oxide-based material is due to the presence of a nonconducting glassy phase present along the grain boundary of the zinc oxide grains, which breaks down when an electric field is applied (Matsouka et al 1970; Lampert 1962). The glassy phase is formed by adding various oxides like $\mathrm{Bi}_{2} \mathrm{O}_{3}, \mathrm{MnO}, \mathrm{CoO}, \mathrm{SiO}_{2}, \mathrm{Sb}_{2} \mathrm{O}_{3}, \mathrm{Cr}_{2} \mathrm{O}_{3}$, etc., to zinc oxide.

The present work describes the development of zinc oxide varistors with $n \geq 25$. The grain growth kinetics during sintering of these ceramics has also been studied.

\section{Experimental techniques}

Zinc oxide varistors were prepared by the well-known powder metallurgical method. A mixture of $94 \mathrm{~mol} \%$ zinc oxide (Waldies $99.7 \%$ pure) and $6 \mathrm{~mol} \%$ of various oxides like $\mathrm{Bi}_{2} \mathrm{O}_{3}, \mathrm{CoO}, \mathrm{Sb}_{2} \mathrm{O}_{3}, \mathrm{Cr}_{2} \mathrm{O}_{3}$ and $\mathrm{MnO}$ (all AR grade) in equal molar ratios were thoroughly mixed in a jar mill for 2 to $6 \mathrm{hr}$. The powder from the jar mill was granulated using PVA as a binder. Tablets of the size $18 \times 2.5 \mathrm{~mm}$ thick were pressed to a green density of 3.2 to $3.3 \mathrm{~g} / \mathrm{cc}$. These tablets were then sintered at temperatures between 1000 to $1350^{\circ} \mathrm{C}$ for various time intervals. The contacts to the sintered tablets were made by various techniques like air-drying silver paint, fire-on-type silver paint, vacuumdeposited aluminium or silver and indium mercury amalgam. The current voltage

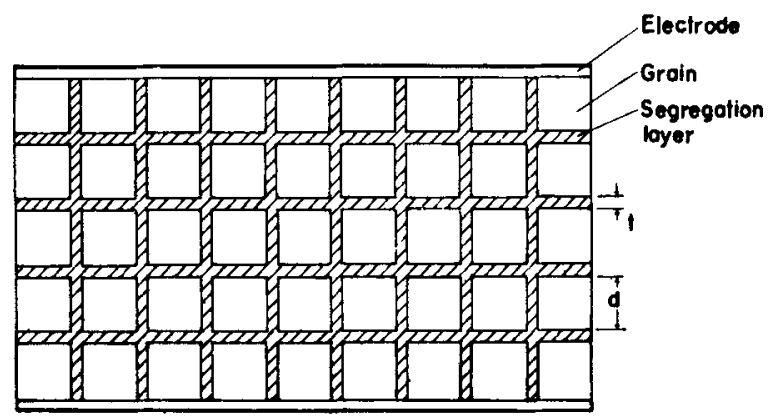

Figure 2. Schematic diagram of microstructure of zinc oxide ceramics.

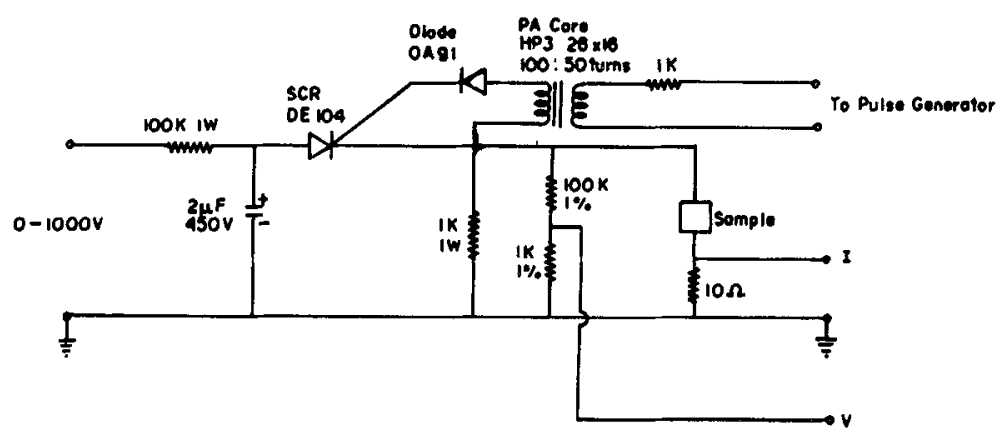

Figure 3. Electronic circuit used to test zinc oxide varistor at high currents using a pulse of 1 msec duration. 


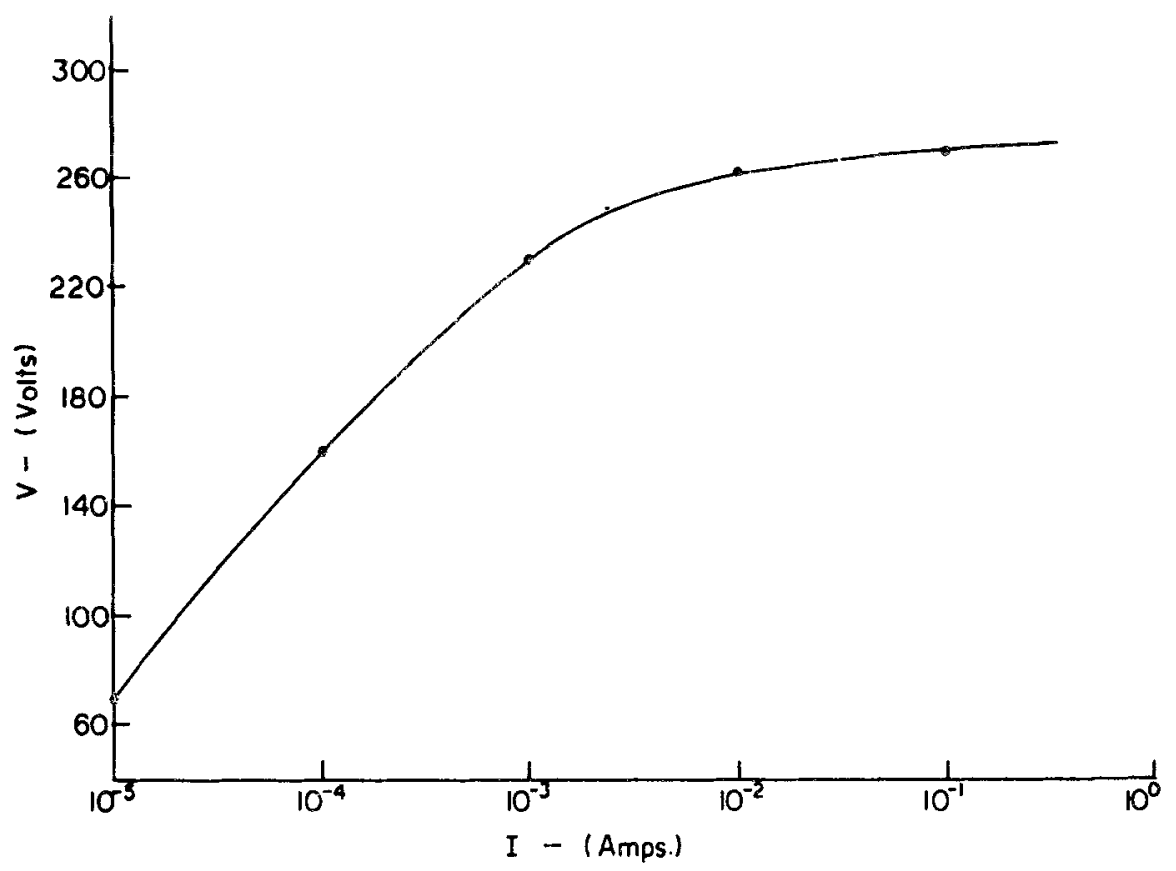

Figure 4. Voltage vs current characteristics of a zinc oxide varistor.



Figure 5. Variation of varistor parameters with sintering temperature. 
characteristic was measured at low current levels using a DC method and at high current levels using a current pulse of $1 \mathrm{~m}$ sec duration according to the circuit given in figure 3 . Microstructure of the specimens was studied after polishing and then etching in a dilute solution of hydrochloric acid.

\section{Results and discussions}

The nonlinear voltage dependence of the current through a zinc oxide varistor is shown in figure 4 . The variation of $n$, the nonlinearity exponent and the electric field, at a curent density of $5 \mathrm{~mA} / \mathrm{cm}^{2}$ with the sintering temperature is shown in figure 5 . It can be seen that as the content of the additives increases, the nonlinearity exponent increases, For $6 \%$ additives content, it decreases with increasing the sintering temperature, whereas for lower additives content it increases with increase in the sintering temperature. At $6 \%$ additive contents there is considerable grain growth at higher sintering temperatures



Figure 6. Microstructure of zinc oxide varistor containing $6 \%$ additives sintered at different temperatures and time intervals is shown. At the grain boundaries of big grains of $\mathrm{ZnO}$ a second phase is clearly visible. 




Figure 7 . Square of grain diameter $\left(D^{2}\right)$ of zinc oxide varistor containing $6 \%$ additives is plotted against sintering time (hr) from which rate constant $K\left(\mathrm{~mm}^{2} /\right.$ hour $)$ can be calculated.

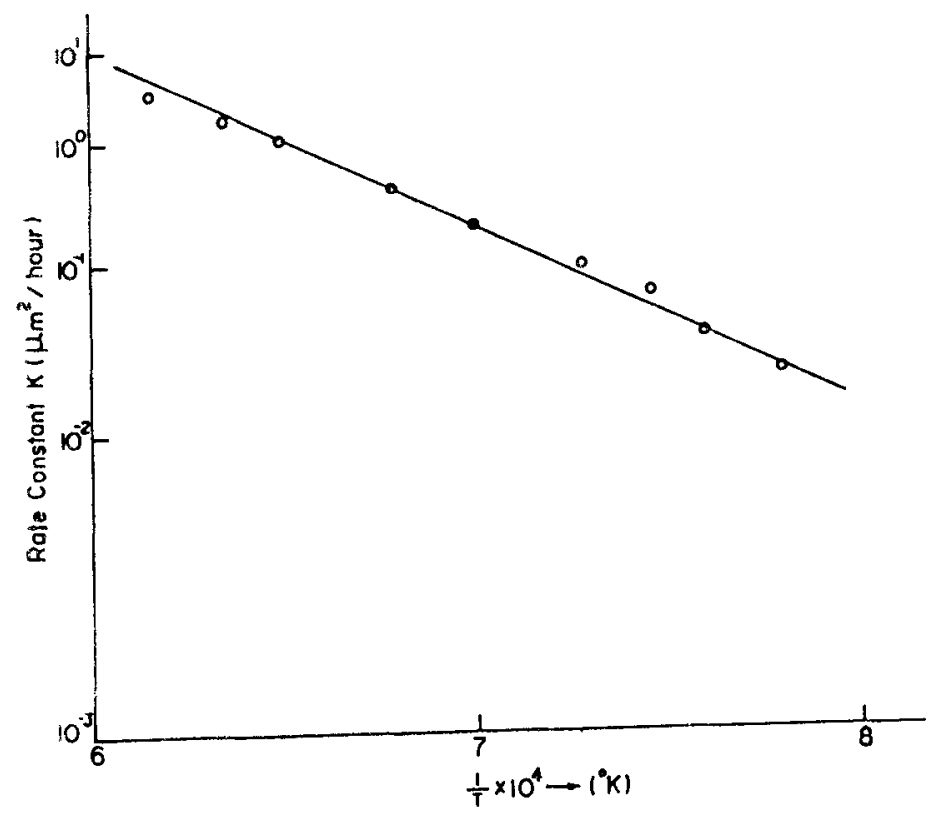

Figure 8. Log of rate constant $K$ us $1 / T$ (Kelvin) [Arrhenius plot] for zinc oxide varistor containing $6 \%$ additives is shown. Activation energy $\sim 65 \mathrm{kcal} / \mathrm{mol}$. 
leading to lower $n$ values. For lower contents, presumably only at higher sintering temperatures, all grains get coated with the insulating glassy phase and $n$ increases with increase in sintering temperature.

Grain growth kinetics during sintering of zinc oxide varistors containing 6 mol\% additive has been studied as shown in figure 6 . Although the grains are not equisized, the presence of a second phase, which is a liquid at sintering temperatures, can be seen at the grain corners. The grain growth kinetics data fits $D^{2}=k t$ at various sintering temperatures as shown in figure 7. The grain growth does not seem to be promoted by the presence of liquid phase at sintering temperatures in which case Lay's analysis should hold giving $D^{3} \sim t$. The activation energy for grain growth was estimated to be $\sim 65 \mathrm{cal} / \mathrm{mol}$ from the Arrhenius plot (figure 8 ) of the rate constants as calculated from the slopes of figure 7 .

\section{References}

Dienel H F 1956 Bell. Lab. Record 34407

Frosca C J 1954 Bell. Lab. Record 3233

Harnden J D Jr, Marzloff F D, Mohris W G and Golden F D 1972 Electronics 4591

Lampert M A 1962 Proc. IRE 501781

Matsouka M, Masuyana T and Ida Y 1969 Jpn. J. Appl. Phys. 81275

Matsouka M, Masuyana T and Ida Y 1970 Jpn. Soc. Appl. Phys. Suppl. 39 p. 94

Matsouka M et al 1970 Proc. I conf. Solid State Devices, Tokyo Jpn. Soc. Appl. Phys. Suppl. p. 94

MCafee K B, Ryder E J, Shockly W and Sparks M 1951 Phys. Rev. 83650

Mckay K G 1954 Phys. Rev. 94887 